\title{
EVALUASI EXPOSURE INDEX TERHADAP FAKTOR EKSPOSI DENGAN METODE 15\% KVP RULE OF THUMB PADA PEMERIKSAAN RADIOGRAFI KEPALA PROYEKSI AP
}

\author{
Shinta Gunawati ${ }^{1}$, Muhammad Irsal ${ }^{1 *}$, Dewi Amalia Marina ${ }^{1}$, Nursama Heru Apriantoro ${ }^{1}$, Mahfud Edy W' \\ 1Politeknik Kesehatan Kementerian Kesehatan Jakarta II \\ Email : muhammad.irsal@poltekkesjkt2.ac.id*
}

Diterima : 14 Juni 2021 . Disetujui : 15 Juli 2021 . Dipublikasikan : 28 Juli 2021

\begin{abstract}
ABSTRAK
Pemanfaatan Computed Radiography (CR) membuat Radiografer menjadi kurang memperhatikan dalam pemilihan faktor eksposi. Sehingga sering terjadi eksposi berlebihan (overexposure) yang membuat pasien menerima dosis radiasi berlebih dan eksposi kurang (underexposure) yang akan menimbulkan noise walaupun sudah dilakukan postprocessing. Penelitian ini bertujuan untuk mendapatkan nilai faktor eksposi yang optimum pada pemeriksaan radiografi kepala dengan menggunakan metode $15 \% \mathrm{kVp}$ Rule of Thumb. Penelitian ini dilakukan di Laboratorium Jurusan Teknik Radiodiagnostik dan Radioterapi pada bulan Maret - Mei 2020, menggunakan metode kuantitatif eksperimental dan observasi terhadap nilai dosis paparan dan kualitas citra pada penggunaan faktor eksposi dengan metode 15\% kVp Rule of Thumb : $42 \mathrm{kV} 128 \mathrm{mAs}, 50 \mathrm{kV} 64 \mathrm{mAs}, 60 \mathrm{kV} 32 \mathrm{mAs}, 72 \mathrm{kV} 16 \mathrm{mAs}, 82 \mathrm{kV} 8 \mathrm{mAs}, 94 \mathrm{kV}$ $4 \mathrm{mAs}, 108 \mathrm{kV} 2 \mathrm{mAs}$ menggunakan phantom pada pemeriksaan radiografi kepala proyeksi AP. Hasil penelitian Variasi faktor eksposi metode $15 \% \mathrm{kVp}$ Rule of Thumb pada pemeriksaan kepala proyeksi AP mempengaruhi nilai sensitivity, dosis paparan, dan kualitas citra, dimana nilai sensitivity yang direkomendasikan memiliki nilai noise paling rendah pada sampel $60 \mathrm{kV} 32 \mathrm{mAs}$ dan $72 \mathrm{kV} 16 \mathrm{mAs}$. Pengaturan faktor eksposi yang optimum dapat menggunakan nilai rentang $\mathrm{kV}$ sebesar $60-72$ dan $\mathrm{mAs}$ dalam rentang 16 - 32 yang menghasilkan nilai sensitivity dalam kategori properly exposed dengan nilai dosis dan noise dalam jumlah minimal pada pemeriksaan radiografi kepala proyeksi AP.
\end{abstract}

Kata kunci : Computed Radiography (CR), metode $15 \%$ kV, Kepala proyeksi AP

\begin{abstract}
The use of Computed Radiography (CR) makes radiographers less concerned with choosing exposure factors. So that it is often overexposure that makes the patient receive excessive radiation doses and underexposure which will cause noise even though has been carried out post-processing. This study aims to obtain the optimum exposure factor value on head radiographs using the $15 \% \mathrm{kVp}$ method Rule of Thumb. This research was conducted at the Laboratory Department of Diagnostic Imaging and Radiotherapy, Polytechnic of Heath Jakarta 2 in March-May 2020, using experimental quantitative methods and observations of the value of exposure dose and image quality in the use of variations of 7 samples of exposure factors with the $15 \% \mathrm{kVp}$ method Rule of Thumb using phantom in radiographic examination AP projection head. The results of the study The variation of the exposure factor of the $15 \%$ kVp method Rule of Thumb : : $42 \mathrm{kV} 128 \mathrm{mAs}, 50 \mathrm{kV} 64 \mathrm{mAs}, 60 \mathrm{kV} 32 \mathrm{mAs}, 72 \mathrm{kV} 16 \mathrm{mAs}, 82 \mathrm{kV} 8 \mathrm{mAs}, 94$ $k V 4 \mathrm{mAs}, 108 \mathrm{kV} 2 \mathrm{mAs}$ on the examination of the AP projection head affected the value sensitivity, exposure dose, and image quality, where the sensitivity recommended value had the value noise lowest the $60 \mathrm{kV} 32 \mathrm{mAs}$ dan $72 \mathrm{kV}$ $16 \mathrm{mAs}$. The optimum exposure factor setting can use the $\mathrm{kV}$ range values of $60-72$ and $\mathrm{mAs}$ in the range $16-32$ which results in values sensitivity in the category properly exposed with dosage and values noise minimal the radiographic examination of the AP projection head.
\end{abstract}

Keywords: Computed Radiography (CR), 15\% kV Method, AP Projection Head 


\section{PENDAHULUAN}

Di era teknologi komputer dan data digital telah dikembangkan teknik pemeriksaan radiografi berbasis komputer yang memudahkan Radiografer dalam menghasilkan radiograf yang lebih berkualitas. Kemudahan ini berasal dari berbagai macam aspek, salah satunya adalah meminimalisir reject film yang sering terjadi pada sistem konvensional. Pada sistem Computed Radiography (CR) gambar dapat dioptimalkan baik ukuran, kontras, maupun densitasnya sebelum dicetak sebagai radiografi. Sehingga pengulangan yang disebabkan oleh ketidaktepatan pemilihan faktor eksposi dapat di minimalisir. Computed Radiography (CR) merupakan sistem radiografi yang dapat mengubah sinyal analog menjadi sinyal digital sehingga mudah diproses dengan pengolahan citra, untuk menangani ketidaktetapan kualitas citra dari kekeliruan dalam pencahayaan. Pada prinsipnya, CR merupakan proses digitalisasi menggunakan image plat yang memiliki lapisan kristal photostimulable (Ningtias, Suryono, \& Susilo, 2016).

Faktor eksposi (faktor penyinaran) adalah faktor yang menentukan dan mempengaruhi kualitas dan kuantitas dari penyinaran radiasi sinar- $x$ dalam pembuatan citra radiografi. Faktor eksposi terdiri dari kVp (Kilo Voltage Peak), mA (mili Ampere), dan s (second) (Sparzinanda, Nehru, \& Nurhidayah, 2017). kVp (Kilo Voltage Peak) adalah satuan beda potensial yang mempengaruhi kualitas sinar-x yang dihasilkan tabung Roentgen dan menjadi indikator kemampuan sinar-x dalam menembus objek. mA (mili Ampere) adalah suatu arus tabung yang mempengaruhi kuantitas sinar-x yang dihasilkan tabung Roentgen dan $s$ (second) adalah faktor yang mempengaruhi waktu lamanya tegangan tabung bekerja selama proses produksi sinar-X. Untuk mendapatkan citra radiografi yang sesuai dengan kriteria gambar, maka perlu di kaji nilai faktor eksposi yang optimum (Savitri \& Sunarno, 2014). Agar mendapatkan faktor eksposi yang optimum dapat diterapkan dengan 15\% kVp Rule of Thumb, dimana jika nilai kV dinaikan $15 \%$, maka nilai mAs turun setengahnya, dan jika nilai $\mathrm{kV}$ turun $15 \%$, maka mAs akan menajdi dua kali lipatnya. (Stewart C Bushong, 2004). Pemanfaatan Computed Radiography (CR) membuat Radiografer menjadi kurang memperhatikan dalam pemilihan faktor eksposi. Sehingga sering terjadi eksposi berlebihan (overexposure) yang membuat pasien menerima dosis radiasi berlebih dan eksposi kurang (underexposure) yang akan menimbulkan noise walaupun sudah dilakukan post-processing. Exposure index pada teknologi Computed Radiography (CR) adalah fasilitas untuk mengetahui terjadinya eksposi berlebihan (overexposure) maupun eksposi kurang (underexposure).

Exposure index adalah sistem dari CR/DR untuk memberikan informasi tentang nilai exposure untuk menghasilkan citra yang optimal (Paul, 2012). Exposure index merupakan parameter pada Computed Radiography (CR) dalam menerangkan jumlah paparan pada Imaging Plate (IP). (Seeram, Davidson, Bushong, \& Swan, 2016). Nilai rentang exposure index didapatkan dari jumlah paparan radiasi yang diterima oleh Imaging Plate (IP). Diperlukan proses pembacaan imaging plate pada image reader untuk mengetahui berapa besar nilai exposure index dalam satu kali eksposi. Hasil dari image reader akan ditampilkan di layar monitor dengan menampilkan hasil citra radiografi dan nilai exposure indexnya. Hal ini dapat dijadikan sebagai patokan Radiografer bahwa pemilihan faktor eksposi berpengaruh pada nilai rentang exposure index. Pencitraan CR dapat memberikan kualitas citra yang optimal dengan menurukan dosis radiasi, namun dalam prakteknya radiografer sulit dalam menentukan exposure index 
yang optimal karena peningkata faktor eksposi pada saat menggunakan CR (Gibson DJ \& Davidson RA, 2012). Kenaikan dosis radiasi disebut dengan 'dose creep', hal ini disebabkan oleh penggunaan faktor eksposi yang lebih tinggi sehingga menyebabkan meningkatnya noise pada citra radiografi (Mc Fadden S, Roding T, De Vries G, Benwell M, Bijwaard H, \& Scheurleer J, 2018). Pada proses akuisisi citra CR memberikan persentasi $100 \%$ untuk indikator underexposure dan $500 \%$ untuk overexposure (Butler ML, Rainford L, Last J, Brennan P, 2010). Dalam upaya optimasi dibutuhkan indikator exposure index (EI) untuk menilai kualitas citra dengan paparan overexposure, exposureideal, underexposure. Hal ini dapat digunakan sebagai panduan indikator dosis radiasi pasien. (Hinojos-Armendáriz VI, Mejía-Rosales SJ, Franco-Cabrera MC, 2018). Oleh karena itu perlu dilakukan evaluasi nilai exposure index terhadap faktor eksposi optimum dengan metode 15\% kVp Rule of Thumb pada pemeriksaan kepala proyeksi AP.

\section{METODE PENELITIAN}

Pengolahan dan analisis data dilakukan berdasarkan dari teori dan data yang diperoleh. Hasil penelitian yang diperoleh disajikan dalam bentuk tabel dan grafik yang kemudian dianalisis secara deskriptif. Analisa data dilakuakan dengan membandingkan perubahan nilai exposure index dengan variasi faktor eksposi penerapan Metode 15\% kVp Rule of Thumb untuk mendapatkan faktor eksposi optimum dengan menambahkan 15\% kenaikan kV kemudian 50\% menurunkan mAs pada setiap kenaikanikan nilai $\mathrm{kV}$ dan menghitung dosis radiasi yang terekam pada citra. Selanjutnya menganalisa nilai noise menggunakan software imageJ. Variasi faktor eksposi di tunjukan pada Tabel berikut :

Tabel 1.Faktor Eksposi dengan Metode 15\% kV Rule of Thumb

\begin{tabular}{ccc}
\hline \multirow{2}{*}{ Sampel } & \multicolumn{3}{c}{ Faktor Eksposi } \\
\cline { 2 - 3 } & $\mathbf{k V}$ & $\mathbf{m A s}$ \\
\hline 1 & 42 & 128 \\
\hline \multirow{2}{*}{ Sampel } & \multicolumn{2}{c}{ Faktor Eksposi } \\
\cline { 2 - 3 } & $\mathbf{k V}$ & $\mathbf{m A s}$ \\
\hline 2 & 50 & 64 \\
4 & 60 & 32 \\
5 & 72 & 16 \\
6 & 82 & 8 \\
7 & 94 & 4 \\
& 108 & 2 \\
\hline
\end{tabular}

Nilai sensitivity merupakan indikator dosis yang tersedia. Dengan nilai sensitivity kita dapat mengetahui berapa nilai dosis yang dikeluarkan. Hasil perhitungan ini didapatkan dari rumus:

$$
\text { Sensitivity }=\frac{200}{\text { exposure to the } I P(m R)}
$$

\section{HASIL DAN PEMBAHASAN}

Gambar 1. menunjukan adanya pengaruh variasi faktor eksposi terhadap nilai sensitivity pada

Penelitian ini dilakukan di Laboratorium Laboratorium Jurusan Teknik Radiodiagnostik dan Radioterapi dengan tujuan mendapatkan nilai faktor eksposi optimum pemeriksaan radiografi phantom kepala yang dilihat dari nilai sensitivity, dosis, dan noise pada pemeriksaan phantom kepala proyeksi AP menggunakan computed radiography dengan metode 15\% kVp Rule of Thumb.

pemeriksaan radiografi phantom kepala proyeksi AP menggunakan computed radiography. Perubahan 


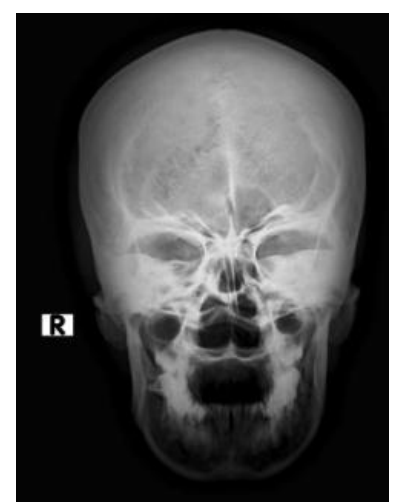

$\begin{array}{ll}\text { kV } & : 40 \\ \text { mAs } & : 128 \\ \text { Sensitivity } & : 605 \\ \text { Paparan } & : 0,33 \mathrm{mR} \\ \text { Sampel 1 } & \end{array}$
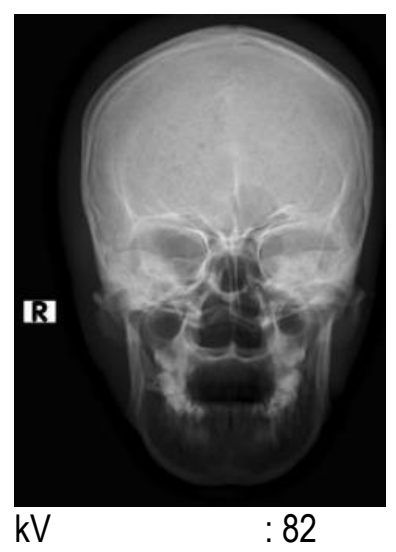

mAs

Sensitivity

Paparan

Sampel 5

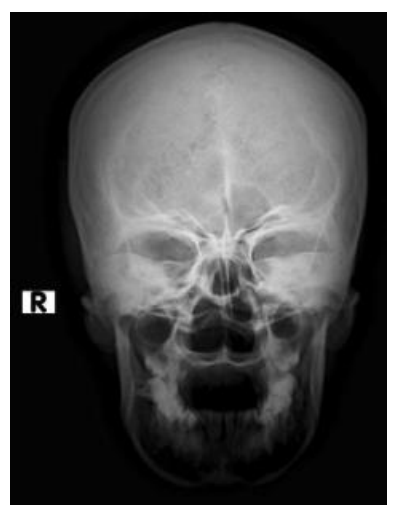

$\mathrm{kV}$

mAs

Sensitivity

Paparan

Sampel 2
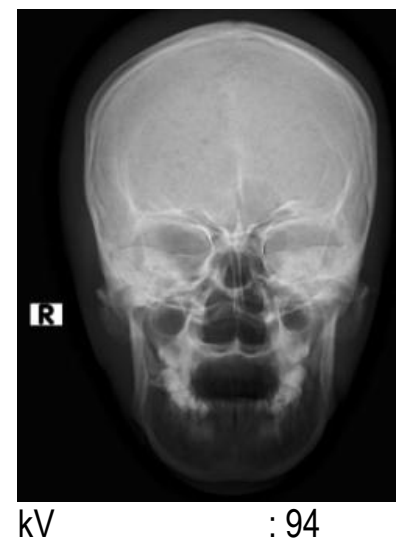

mAs

Sensitivity

Paparan

Sampel 6

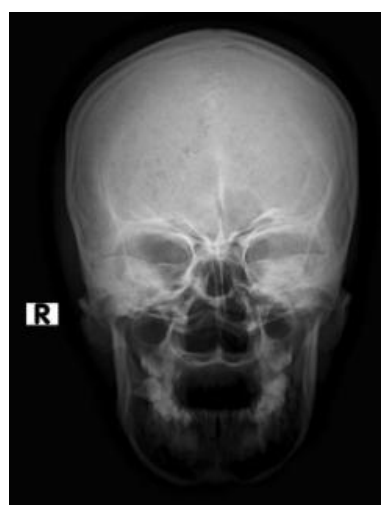

$\mathrm{kV}$

mAs

Sensitivity

Paparan

Sampel 3
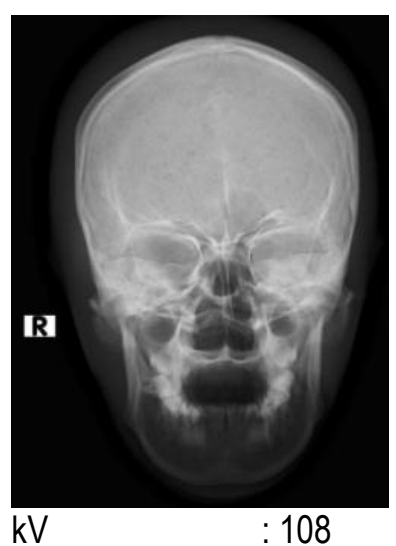

mAs $: 2$

Sensitivity $: 200$

Paparan : :1 mR

Sampel 7
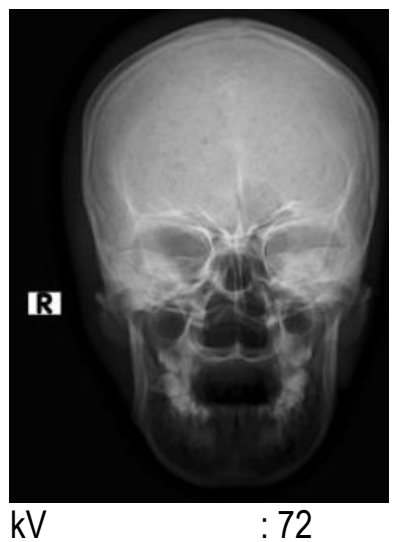

mAs $: 16$

Sensitivity $: 191$

Paparan $\quad: 1,04 \mathrm{mR}$

Sampel 4

Gambar 1.Citra hasil variasi faktor eksposi

faktor eksposi dengan menggunakan metode $15 \% \mathrm{kVp}$

Rule of Thumb memperlihatkan adanya penurunan

nilai sensitivity pada sampel eksposi ke-1 - sampel eksposi ke-5 dan penaikan pada sampel eksposi ke-5 - sampel eksposi ke-7. Hal ini dikarenakan pada Fuji service manual ada beberapa faktor yang mempengaruhi nilai sensitivity, seperti scatter, jarak, kolimasi, pemeriksaan yang dipilih, delay time processing, mAs, dan atenuasi (Rochmayanti, Darmini, \& Jannah, 2018), selain itu Selain itu dibutuhkan radiografer yang berpengalaman dalam penilaian kualitas citra subjektif, karena dari hasil citra pada Gambar 1 tidak terlihat perbedaan yang signifikan dari setiap sampel percobaan ini mengidentifikasi bahwa metode optimasi dapat dilakukan (Bond, 1999). Pada sampel ke-1 dengan menggunakan faktor eksposi $42 \mathrm{kV}$ dan $128 \mathrm{mAs}$ mendapatkan hasil citra radiografi dengan nilai sensitivity sebesar 605 dan eksposi sampel ke-2 dengan faktor eksposi $50 \mathrm{kV}$ dan $64 \mathrm{mAs}$ mendapatkan nilai sensitivity sebesar 439. Kedua sampel tersebut memiliki nilai sensitivity dalam kategori underexposure. Sesuai dalam teori bahwa rentang sensitivity yang nilainya dibawah 100 termasuk ke dalam kategori overexposure dan underexposure jika nilainya diatas 400 (Adler \& Carlton, 2016). Sedangkan eksposi sampel ke-3, 4, 5, 6 , dan 7 memiliki nilai sensitivity dalam kategori 
properly exposed yaitu, berada pada rentang nilai sensitivity 100-400.

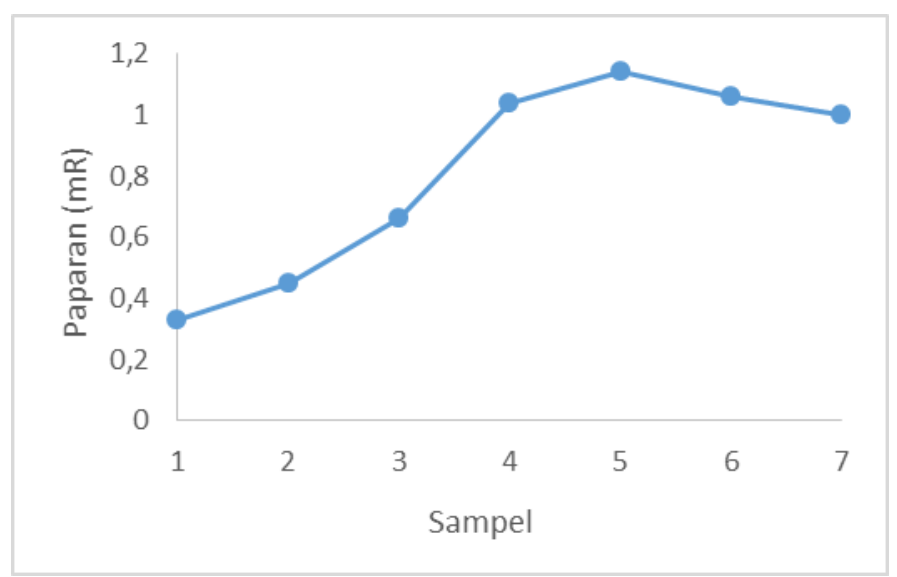

Gambar 2. Grafik Analisa Paparan (mR)

Gambar 2. Hasil perhitungan paparan sensitivity yang didapat. Semakin rendah nilai menggunakan persamaan 1, pada sampel ke-5 yaitu sebesar 1,14 mR dengan nilai sensitivity terkecil yaitu sebesar 175 dan nilai dosis permukaan terendah terdapat pada sampel ke-1 yaitu $0,33 \mathrm{mR}$ dengan nilai sensitivity sebesar 605 yang masuk kedalam kategori underexposure. Begitu pula dengan nilai dosis kedua paling rendah yaitu pada sampel ke-2 dengan nilai dosis sebesar $0,45 \mathrm{mR}$ dan nilai sensitivity 439 yang masuk kedalam kategori underexposure. Beda halnya dengan nilai dosis terendah ketiga yaitu pada sampel ke-3 dengan nilai dosis sebesar 0,66 dan nilai sensitivity sebesar 303 yang masuk kedalam kagegori properly exposure. Hal ini membuktikan rendah atau sensitivity maka semakin tinggi nilai dosis yang didapatkan (Seeram, 2019)

Data hasil analisa citra menggunakan Image $J$ untuk menghasilkan nilai noise radiografi phantom kepala dengan menggunakan variasi faktor eksposi berdasarkan metode $15 \% \mathrm{kVp}$ Rule of Thumb yang ditunjukan pada tabel Tabel 2. Citra radiografi dinyatakan berkualitas apabila mampu memberikan informasi yang jelas mengenai keadaan suatu objek yang diperiksa. Untuk mengetahui kualitas citra radiografi pada computed radiography ditentukan oleh beberapa faktor, salah satunya yaitu nilai noise (Bontrager \& Lampignano, 2014). tingginya dosis berbanding terbalik dengan nilai

Tabel 2. Analisa citra Image $J$

\begin{tabular}{cccc}
\hline Sampel & $\begin{array}{c}\text { Exposure Index } \\
\text { (Sensitivity) }\end{array}$ & Mean & $\begin{array}{c}\text { Standar } \\
\text { Deviasi }\end{array}$ \\
\hline 1 & 605 & 725,8 & 285,1 \\
2 & 439 & 754,1 & 272,3 \\
3 & 303 & 759,5 & 265,7 \\
4 & 191 & 735,6 & 267,2 \\
5 & 175 & 710,9 & 273,2 \\
6 & 187 & 685,1 & 279,7 \\
7 & 200 & 664,3 & 281,4 \\
\hline
\end{tabular}

Pada sampel ke-1 didapatkan hasil citra 272,362. Lalu pada sampel ke-3 nilai noise sebesar dengan nilai noise yaitu 285,122 . Kemudian pada hasil 265,666 . Pada sampel ke-4 nilai noise yang diperoleh citra sampel ke-2 mendapatkan nilai noise sebesar sebesar 267,277. Sampel ke-5 mendapatkan nilai 
noise sebesar 273,267 . Di sampel ke-6 nilai noise sebesar 279,794. Pda sampel terakhir yaitu sampel ke-7 mendapatkan nilai noise sebesar 281,426. Jika sampel di urutkan dari jumlah noise terbesar ke jumlah noise terkecil sampel ke-1 menududuki tempat pertama, lalu di susul dengan sampel ke-7, sampel ke6 , sampel ke-5, sampel ke-2, sampel ke-4, dan sampel ke-3 yang merupakan sampel yang memiliki nilai noise terkecil. Data dari hasil penelitian menggunakan software imageJ menunjukan bahwa banyaknya noise yang ada di sekitar obyek ditentukan oleh besarnya standar deviasi. Semakin besar nilai standar deviasi, maka semakin banyak noise yang ada. Nilai noise yang tinggi disebabkan nilai $m A s$ yang besar dan semakin besar nilai $\mathrm{kV}$ maka nilai noise semakin tinggi (Wibowo, Murti, \& Prabowo, 2015).

\section{SIMPULAN DAN SARAN}

Variasi faktor eksposi metode 15\% kVp Rule of Thumb pada pemeriksaan kepala proyeksi AP mempengaruhi nilai sensitivity, dosis paparan, dan kualitas citra, dimana nilai sensitivity yang direkomendasikan memiliki nilai noise paling rendah pada sampel ke-3 dan ke-4. Pengaturan faktor eksposi yang optimum dapat menggunakan nilai rentang $\mathrm{kV}$ sebesar 60 - 72 dan mAs dalam rentang 16 - 32 yang menghasilkan nilai sensitivity dalam kategori properly exposed dengan nilai dosis dan noise dalam jumlah minimal pada pemeriksaan radiografi kepala proyeksi AP.

\section{DAFTAR PUSTAKA}

Ningtias, D. R., Suryono, S., \& Susilo. (2016). Pengukuran Kualitas Citra Digital Computed Radiography Menggunakan Program Pengolah Citra. Jurnal Pendidikan Fisika Indonesia, 12. https://doi.org/10.15294/jpfi.v12i2.5950

Savitri, R. E., \& Sunarno, S. (2014). Optimasi Faktor Eksposi Pada Sistem Radio Optimasi Faktor
Eksposi Pada Sistem Radiografi Grafi Digital Menggunakan Analisis Cnr (Contrast To Noise Ratio). Unnes Physics Journal, 3(1).

Bushong, Stewart C. (2004). Radiologic Science for Technologists Workbook and Laboratory Manual (8th ed). Missouri: Elsevier Mosby.

Paul, T. S. R. (2012). Radiologic Technology at a Glance (1st ed). New York: Delmar Cengage Learning.

Seeram, E., Davidson, R., Bushong, S., \& Swan, H. (2016). Optimizing the exposure indicator as a dose management strategy in computed radiography. Radiologic Technology, 87(4), 380391.

Gibson DJ, Davidson RA. Exposure Creep in Computed Radiography. A Longitudinal Study. Acad Radiol. 2012;

Mc Fadden S, Roding T, De Vries G, Benwell M, Bijwaard $\mathrm{H}$, Scheurleer J. Digital imaging and radiographic practise in diagnostic radiography: An overview of current knowledge and practice in Europe. 2018 [cited 2020 Jul 18]; Available from: https://doi.org/10.1016/j.radi.2017.11.004

Butler ML, Rainford L, Last J, Brennan PC. Are exposure index values consistent in clinical practice? A multi-manufacturer investigation. Radiat Prot Dosimetry. 2010;

Hinojos-Armendáriz VI, Mejía-Rosales SJ, FrancoCabrera MC. Optimisation of radiation dose and image quality in mobile neonatal chest radiography. Radiography. 2018;

Rochmayanti, D., Darmini, D., \& Jannah, M. (2018). Faktor Determinan Kolimasi, Ukuran Imaging Plate Dan Delay Time Processing Terhadap Exposure Index. Jurnal Riset Kesehatan, 6(2), 1. https://doi.org/10.31983/jk.v6i2.2910

Bond N. Optimization of image quality and patient exposure in chest radiography. Radiography. 1999;

Adler, A., \& Carlton, R. (2016). Introduction to Radiologic and Imaging Sciences and Patient Care (6th ed). Missouri: Elsevier.

Seeram, E. (2019). Digital Radiography: Physical Principles and Quality Control (2nd Ed, ed.). Sydney: Springer.

Bontrager, K. L., \& Lampignano, J. P. (2014). 
Textbook Of Radiographic Positioning And Related Anatomy. In Journal of Chemical Information and Modeling https://doi.org/10.1017/CBO9781107415324.004
Wibowo, A. S., Murti, G., \& Prabowo, A. (2015). Analisis Perubahan Kv Dan Mas Terhadap Kualitas Gambar Dan Dosis Radiasi. 2(1), 129133. 